\title{
Sports injuries and psychological aspects of pain perception of athletes
}

\author{
Jakub Sciranka and Adriana Kaplánová ${ }^{凶}$ \\ Department of Sport Science in Educology and Humanities, Faculty of Physical Education and Sports, Comenius University \\ in Bratislava, Bratislava, Slovakia
}

\begin{abstract}
Background: Injury is one of the risks of performing regular sports activities, which causes mild to severe physical discomfort and emotional distress for athletes. Objective: As there is not much research on the psychological aspects of pain perception of athletes, the main purpose of this study was to investigate differences in pain coping styles according to gender and type of sport. Methods: The sample consisted of 147 athletes (101 men, 46 women) who reported a previous sports-related injury, with an average age of $20.82 \pm 1.61$ years, involved in individual $(n=59)$ and team $(n=88)$ sports. The pain perception was evaluated by Sports Inventory for Pain (SIP15) comprised of three subscales: coping by direct action, catastrophizing, and somatic awareness. Results: We found that men perceive pain in sport more intensely and sensitively than women ( $p=.01, r=.21)$. Nevertheless, men consider pain to be more bearable and give up less than women $(p=.05, r=.16)$. In individual and team sports, we did not find significant differences in response to painful stimuli, but in terms of giving up due to the perceived pain, the athletes of individual sports scored higher values than athletes of team sports $(p=.04, r=.17)$. In coping by direct action, we also did not find significant differences between gender or types of sports. Conclusions: The results of our research suggest that pain perception is one of the factors influencing giving up in the sport. Therefore, we recommend that this aspect be considered in psychological preparation and that the efforts of sports psychologists should focus on eliminating escape reactions, especially for women, which would contribute to higher mental resilience and effective management of painful obstacles. We also recommend implementing psychological preparation aimed at overcoming pain more in individual sports, because it seems that individual athletes can handle pain much more difficultly than collective athletes.
\end{abstract}

Keywords: pain coping styles, somatic, emotions, distress, regular sports activities, sports psychology

\section{Introduction}

Regular physical activity is often associated with higher physical and mental stress and with exposure to various painful stimuli on one's own body (Cook \& Koltyn, 2000; Meyers et al., 2001). Pain in sports serves as a warning of impending or already present trauma (Lindner \& Caine, 1990), according to Gregor (2013) it may be perceived as acute and chronic (lasts three to six months). Kováč (2010) adds psychological pain, which can be caused by stimuli or situations from the personal or environmental area. Athletes in various sports are often forced to overcome pain, which is extremely difficult for the psychological processing of perceived pain (Epstein, 2011). According to Young et al. (1994), the ability to tolerate pain is a reward of behavior that shows character and separates men from boys. Deroche et al. (2011) suggest, that athletes who ignore pain are able to maintain their athletic commitment despite the perception of pain.

In the context of sport, higher attention has been paid to the athlete's response to injury. There is evidence that pain tolerance differs significantly between athletes and non-athletes (Sullivan et al., 2000; Tesarz et al., 2012). Differences in the tolerance of perceived pain according to the type of sports activity have been shown by the study of Raudenbush et al. (2012) who studied the perception of pain in contact and non-contact sports. The athletes engaged in contact sports showed a higher pain tolerance and perceive lower pain intensity than athletes in non-contact sports. Contact athletes are characterized by a desire to endure pain and perceive it positively which may also be due to pain coping styles and the development of tolerance for pain perception (Thornton et al., 2017). Research by Meyers et al. (1992) also showed higher scores in coping and somatic awareness, and lower catastrophizing scores in nontraditional/extreme competitors as compared to traditional athletes (Meyers et al., 2015). In addition, the perception of pain has also been shown to be a significant predictor of sports performance (Meyers et al., 2001). Gordon et al. (2013) found differences in pain perception between cyclists at different performance levels. Cyclists with Olympic level aerobic capacity scored higher in total pain-coping response than those with average aerobic fitness. Griffith et al. (2006) reported that the Sports Inventory for Pain

\footnotetext{
$\triangle$ Corresponding author: Adriana Kaplánová, e-mail adriana.kaplanova@uniba.sk, ORCID ${ }^{\circledR}$ record https://orcid.org/0000-0001-7548-5805 Article history: Received January 31 2021, Accepted October 14 2021, Published November 82021

Copyright: (c) 2021 The Author(s). Published by Palacký University Olomouc. This is an open access article distributed under the terms of the Creative Commons Attribution License (https://creativecommons.org/licenses/by/4.0/), which permits unrestricted use, distribution, and reproduction in any medium, provided the original author and source are credited. This license does not cover any third-party material that may appear with permission in the article.
} 
differentiated perceived pain between experienced and novice base jumpers. Similarly, Thornton et al. (2017), who pointed out the differences in pain experience between novice and experienced contact-sports athletes. Due to age, effective pain management abilities have been found in older athletes than in younger athletes (Meyers et al., 2008). There is also evidence of different pain coping styles of athletes currently injured and non-injured, the injured athletes show significantly higher scores in catastrophizing (Salma \& Meyers, 2019).

Research has also shown gender differences in pain perception. According to a study by Paller et al. (2009), women perceive more intensive clinical pain and showed a higher sensitivity to experimentally induced pain compared to men. Wise et al. (2002) reported that psychosocial factors can be attributed to differences in perceived pain between the gender. According to the authors, it appears that gender-role expectations of pain do play a part in determining an individual's pain report and may be contributing to the gender differences in the laboratory setting. Bartley and Fillingim (2013) add, that psychosocial processes such as pain coping and early-life exposure to stress may also explain gender differences in pain, in addition to stereotypical gender roles that may contribute to differences in pain expression. Also, such differences in pain threshold and pain tolerance can be influenced by sexual hormones (Wiesenfeld-Hallin, 2005), such as cortisol or estradiol (De Castro et al., 2020). Emerging evidence suggests that genotype and endogenous opioid functioning play a causal role in these disparities, and considerable literature implicates sex hormones as factors influencing pain sensitivity (Bartley \& Fillingim, 2013). A significant difference in pain perception among gender was found by heat induction, in favor of men (Paulson et al., 1998). Significant differences between gender in pain coping style were observed among men and women patients undergoing knee reconstruction and rehabilitation (Wooten et al., 2002). The same, significant differences in pain coping styles were observed in the research sample of students receiving collegiate athletic scholarships and students not receiving such scholarships. Men scored significantly higher than women in coping by direct action (Bourgeois et al., 2009). Encarnacion et al. (2000) found subtle differences in men and women ballet dancers. Although there are studies suggesting gender differences in perceived pain (Bourgeois et al., 2009; Paller et al., 2009; Paulson et al., 1998; Wiesenfeld-Hallin, 2005; Wooten et al., 2002), as well as studies pointing to differences in sports (Meyers et al., 2015; Raudenbush et al., 2012; Thornton et al., 2017), there is still a lack of more extensive research in the context of sport.

The presented study aims to examine the pain perception of athletes according to gender and type of sport. For this reason, we decided to assess whether there are significant differences in pain coping styles among athletes with respect to gender and type of sport. We assume that we confirm the gender differences in perceived pain, as well as the differences in pain coping styles between individual and team sports.

\section{Methods}

\section{Participants}

The sample consisted of 147 athletes (101 men, 46 women) who reported a previous sports-related injury, with a range of ages 19-27 years, engaged in individual $(n=59)$, and team $(n=88)$ sports. The average age was $20.82 \pm 1.61$ years, and the average sport age was $11.04 \pm 4.16$ years. To ensure an adequate size of the sample, the participants were selected from the Faculty of Physical Education and Sport, Comenius University in Bratislava. The sample included athletes competing in the following sports: football $(n=59)$, ice hockey $(n=8)$, track and field $(n=16)$, volleyball $(n=8)$, handball $(n=7)$, basketball $(n=6)$, combat sports $(n=10)$, dance sport $(n=10)$, gymnastics $(n=12)$, cycling $(n=3)$, tennis $(n=3)$, weightlifting $(n=4)$, golf $(n=1)$.

\section{Instruments}

Sports Inventory for Pain - SIP15 (Bourgeois et al., 2009) is a revised version of the original Sports Inventory for Pain by Meyers et al. (1992) which is used to measure pain caused by an injury. The SIP15 is a 15-item inventory comprising three scales: coping by direct action, catastrophizing, and somatic awareness. A personal coping resources composite provides an overall index of ability to cope with pain. Participants respond on a 5-point Likert scale from strongly disagree to strongly agree.

Coping by direct action is a positive style of pain management concerning pain and assesses the extent to which someone uses direct pain coping strategies. Athletes who score high on this scale tend to take a positive approach to pain and are prepared to endure it. The catastrophizing scale measures whether individuals think about pain, feel unbearable, or simply give up when they are in pain. High scores on this scale indicate high catastrophization. The somatic awareness scale assesses whether someone is hyposensitive or hypersensitive to pain stimuli, with a high score indicating hypersensitivity. In our study, the reliability of the SIP15 showed acceptable values for three scales: coping by direct action (.82), catastrophizing (.74), and somatic awareness (.54). SIP15 appears to be a reliable tool for measuring pain coping strategies.

\section{Procedures}

The SIP15 was applied by a sports psychologist with years of experience in the field. The inventory was provided in a single booklet, which was given to athletes. In all the cases, the inventory was filed anonymously, and participation in the study was entirely voluntary. The study design was approved by the Ethics Committee of Comenius University in Bratislava, Slovakia. All participants were informed about the aims, methods of data collection, and their use for research purposes. In addition, all participants gave written informed consent in accordance with the Declaration of Helsinki.

\section{Statistical analysis}

The study has a comparative research design that compares pain coping styles of athletes. We used the SPSS statistical 
software (Version 23 for Windows; IBM, Armonk, NY, USA) to process and evaluate the obtained data. Descriptive statistics were used to give an indication of mean scores on subscales of coping by direct action, catastrophizing, and somatic awareness athletes. The Shapiro-Wilk test of normality was applied to examine the data distribution. Due to the nonparametric distribution of the data, MannWhitney $U$-test was used for comparison. A level of significance was set at .05 . The effect size was calculated using $Z / \sqrt{ } N$, whereby a small effect is in an interval $.10 \leq r<.30$, a medium effect is in an interval $.30 \leq r<.50$, and a large effect is $r \geq .50$.

\section{Results}

Table 1 shows the point values achieved by men and women in the SIP15. From the above it is clear that in catastrophizing women scored higher than men $(p=.05, r=.16)$ and in somatic awareness men scored higher than women $(p=.01, r=.21)$. In both cases, the results were significant and with a small effect size. In coping by direct action, we did not find significant gender differences $(p=.67$, $r=.03)$, as well as in personal coping resources $(p=.58$, $r=.05)$.

According to the type of sport (Table 2), athletes did not differ in the perception of pain, with the exception of catastrophizing, where we found statistically differences with a small effect size $(p=.04, r=.17)$. Higher scores were achieved by individual athletes compared to team athletes. In coping by direct action $(p=.46, r=.06)$, somatic awareness $(p=.04, r=.17)$, personal coping resources $(\mathrm{p}=.06, \mathrm{r}=.16)$ we did not find significant differences by type of sport.

\section{Discussion}

The present study provides evidence that there are some differences in the perception of pain in the sport between men and women in the somatic awareness and catastrophizing dimensions.

We found that men perceive pain in sport more intensely and sensitively than women. Similar results were obtained by Bourgeois et al. (2009), who conducted research on university students, also by Meyers et al. (2001) in rodeo athletes, and by Wooten et al. (2002) in presurgical patients. The results of Encarnacion et al. (2000) showed the same trend of pain perception among men ballet dancers. According to Meyers et al. (1992), this difference may imply a tendency for men to be hypersensitive, or to be more anxious (Minev et al., 2017). However, this finding partially refutes the concepts of men's pain resilience in sport (Young et al., 1994). From the above, it can be assumed that a more intense and sensitive perception of pain in men may also be due to the nature of the sport. Men are usually physically stronger, faster, more persistent in physical activity than women (Logan \& Medford, 2011; Thibault et al., 2010). This is also the reason why gender differences are considered in competitions. Given these men's physical predispositions, it can be assumed that even injuries suffered by men, especially in contact sports, can be more serious than those in women, which may be a response to more intense pain in sport.

We found that statistically higher scores were achieved by women in catastrophizing, which is consistent with the study by Encarnacion et al. (2000), in which women's ballet dancers perceived pain as more unbearable and easier to give up compared to men. A similar trend of pain catastrophizing has been observed in college athletes (Bourgeois et al., 2009), and rodeo athletes (Meyers et al., 2001). According to Wahl et al. (2019), gender is one of the predictors of catastrophic pain in sport. This gender difference follows the research and theory suggesting that women are more likely than men to be emotionally expressive focused in managing life stresses, including pain (Sullivan et al., 2001; Unruh, 1996; Wood \& Karten, 1986).

Table 1 Differences in pain coping styles in sport by gender

\begin{tabular}{|c|c|c|c|c|c|c|c|}
\hline \multirow[b]{2}{*}{ Sports Inventory for Pain } & \multirow[b]{2}{*}{ Subscale range } & \multicolumn{2}{|c|}{ Men $(n=101)$} & \multicolumn{2}{|c|}{ Women $(n=46)$} & \multirow[b]{2}{*}{$p$} & \multirow[b]{2}{*}{$r$} \\
\hline & & $M$ & $S D$ & $M$ & $S D$ & & \\
\hline Coping by direct action & $7-35$ & 22.66 & 4.57 & 23.08 & 3.61 & .67 & .03 \\
\hline Catastrophizing & $5-25$ & 11.83 & 2.94 & 12.70 & 3.28 & .05 & .16 \\
\hline Somatic awareness & $3-15$ & 10.72 & 2.20 & 9.72 & 2.21 & .01 & .21 \\
\hline Personal coping resources & & 10.55 & 5.34 & 10.26 & 5.34 & .58 & .05 \\
\hline
\end{tabular}

Note. $r=$ effect size.

Table 2 Differences in pain coping styles in sport by type of sport

\begin{tabular}{|c|c|c|c|c|c|c|c|}
\hline \multirow[b]{2}{*}{ Sports Inventory for Pain } & \multirow[b]{2}{*}{ Subscale range } & \multicolumn{2}{|c|}{ Individual sports $(n=59)$} & \multicolumn{2}{|c|}{ Team sports $(n=88)$} & \multirow[b]{2}{*}{$p$} & \multirow[b]{2}{*}{$r$} \\
\hline & & $M$ & $S D$ & $M$ & $S D$ & & \\
\hline Coping by direct action & $7-35$ & 22.36 & 4.18 & 23.09 & 4.35 & .48 & .06 \\
\hline Catastrophizing & $5-25$ & 12.71 & 3.26 & 11.69 & 2.87 & .04 & .17 \\
\hline Somatic awareness & $3-15$ & 10.22 & 2.04 & 10.53 & 2.37 & .28 & .09 \\
\hline Personal coping resources & & 10.68 & 5.20 & 10.58 & 5.19 & .06 & .16 \\
\hline
\end{tabular}

Note. $r=$ effect size 
In coping by direct action, we did not find the difference between men and women. Similarly, no significant difference was also found in rodeo-athletes (Meyers et al., 2001), college athletes (Williams, 2012), and college athletes who receive an athletic scholarship (Bourgeois et al., 2009). Although we have observed different manifestations of perceived pain experiencing between gender (men experience pain more sensitively, and women tend to give up in pain), it is likely that the positive pain coping strategies are at a similar level between gender.

We also found no significant difference in personal coping resources between men and women. Similarly, no significant difference was observed in college athletes who receive an athletic scholarship (Bourgeois et al., 2009). This lack of significance in individual coping ability between gender can be attributed to the various severity of injuries athletes perceived, or different personality traits such as masculinity (Masten et al., 2014).

Comparing athletes in our study to ballet dancers (Encarnacion et al., 2000), and rodeo athletes (Meyers et al., 2001) both men and women showed lower scores in positive pain coping styles. This difference can be explained that ballet dancers and rodeo athletes are exposed to more painful stimuli/dangerous environments in their sports specialization than participants in our study (e. g. football, track \& field, volleyball). We can say that athletes in our study may have a less positive approach to pain than ballet dancers or rodeo athletes.

According to the type of sport significant difference was observed in catastrophizing among athletes involved in individual and team sports, athletes involved in individual sports scored higher. A similar result was reported by Wandner et al. (2011) when individual athletes tend to perceive pain to be more legitimate than did team sports. This finding of our research partly refutes the evidence that athletes involved in individual sports have higher ego orientation, than team-sport athletes (Hanrahan \& Cerin, 2009; Nicholls et al., 2009). The significantly higher score in catastrophizing by individual athletes can be explained by less frequent or less intense contact with teammates than their team sports counterparts. Those athletes might be less influenced by teammates and feel less intensely the impact of their views on what to do about pain and injuries (Nixon, 1994). This result can also be explained by the higher number of women participating in individual sports, in this study. Participants in individual sports showed a similar tendency to catastrophize as ballet performers (Encarnacion et al., 2000). Athletes in individual sports showed a less-positive approach to pain and are less prepared to endure it than rodeo athletes (Meyers et al., 2001), and ballet performers (Encarnacion et al., 2000).

According to the type of sport no significant difference was observed in coping by direct action and somatic awareness among athletes involved in individual and team sports, similar results were found by Williams (2012) examining college athletes. The same level of positive pain coping strategies among the types of sports was observed in pain-coping in response to heat in both individual and team sports (track and field, basketball) by Sternberg et al.
(1998). Nixon (1996) explained the nonsignificant differences between individual and team sports by the pervasiveness and normalcy of pain and injury experiences in all kinds of sports. Coping by direct action and somatic awareness seem to be the strong predictors of pain interference with performance (Bourgeois et al., 2009), thus, a similar level of these pain coping styles may be affected by previous injury or painful experiences. The sporting age of participants could play a role in non-significant differences in these scales (Griffith et al., 2006; Thornton et al., 2017). Also, the lack of significance can be attributed to various types of sports included in the study such as combat sports, and ice hockey, which are highly contact sports, but in our study, they are divided as an individual (combat sports) and team (ice hockey) sports (Raudenbush et al., 2012; Thornton et al., 2019), or the gender of participants (Wahl et al., 2019).

No significant difference in personal coping resources among athletes involved in individual and team sports can be explained by various types of sports involved and gender differences. Although no significant difference was observed in individual pain ability in terms of sports types, the confirmed small effect size suggests that future research with a larger number of participants may show significant differences between athletes in individual and team sports.

The findings of this research may have influenced potential limitations. Only athletes with a previous injury were involved in the study of pain perception in sport. As there are a limited number of people, we recommend that research be expanded in the future in terms of the severity of injuries, which may be another factor influencing perceived pain.

\section{Conclusions}

The present study provides evidence that there are some differences in the perception of pain in the sport between men and women, as well as between individual and team athletes. We found that men perceive pain in sport more intensely and sensitively than women. However, men consider pain to be more bearable and give up less than women, which must also be considered in the psychological training of athletes. We also found that the psychological training of athletes should also consider the type of sport, as according to the results of our study, individual sports athletes gave up more often than team athletes after exposure to painful stimuli.

\section{Acknowledgments}

We would like to thank the athletes who took part in the study. The study was supported by The Ministry of Education, Science, Research and Sport of the Slovak Republic (grant VEGA 1/0523/19).

\section{Conflict of interest}

The authors report no conflict of interest. 


\section{References}

Bartley, E. J., \& Fillingim, R. B. (2013). Sex differences in pain: A brief review of clinical and experimental findings. British Journal of Anaesthesia, 111(1), 52-58. https://doi.org/10.1093/bja/aet127

Bourgeois, A. E., Meyers, M. C., \& LeUnes, A. (2009). The Sports Inventory for Pain: Empirical and confirmatory factorial validity. Journal of Sport Behavior, 32(1), 19-35.

Cook, D. B., \& Koltyn, K. F. (2000). Pain and exercise. International Journal of Sport Psychology, 31(2), 256-277.

De Castro, J. B. P., Lima, V. P., Dos Santos, A. O. B., Da Silva, G. C. P. S. M., De Oliveira, J. G. M., Da Silva, J. N. L., \& Vale, R. G. D. S. (2020). Correlation analysis between biochemical markers, pain perception, low back functional disability, and muscle strength in postmenopausal women with low back pain Journal of Physical Education and Sport, 20(1), 24-30. https://doi.org/10.7752/ ipes.2020.01003

Deroche, T., Woodman, T., Stephan, Y., Brewer, B. W., \& Le Scanff, C. (2011). Athletes' inclination to play through pain: A coping perspective. Anxiety, Stress \& Coping, 24(5), 579-587. https://doi.org/10.1080/10615806.2011.552717

Encarnacion, M. G., Meyers, M. C., Ryan, N. D., \& Pease, D. (2000). Pain coping styles of ballet performers. Journal of Sport Behavior, 23(1), 20-32.

Epstein, D. (2011). The truth about pain: It's in your head. Sports Illustrated, 115(5), 58-66.

Gordon, J., Meyers, M. C., \& Parker, A. (2013). Coping styles, hardiness, and aerobic performance of competitive male cyclists. In Applied Recreational Research and Programming Annual (Vol. 3, pp. 31-58). American Press.

Gregor, T. (2013). Psychológia športu [Sport psychology]. Mauro.

Griffith, J. D., Hart, C. L., Goodling, M., Kessler, J., \& Whitmire, A. (2006) Responses to the Sport Inventory for Pain among BASE jumpers. Journal of Sport Behavior, 29(3), 242-254.

Hanrahan, S. J., \& Cerin, E. (2009). Gender, level of participation, and type of sport: Differences in achievement goal orientation and attributional style. Journal of Science and Medicine in Sport, 12(4), 508-512. https://doi.org/10.1016/i. isams.2008.01.005

Kováč, D. (2010). Emócie v kogníciách: Zobudíme šípkovú ruženku? [Emotion in cognition]. In I. Ruisel \& A. Prokopčáková (Eds.), Kognitívny portrét človeka (pp. 205-235). The Institute of Experimental Psychology SAS .

Lindner, K. J., \& Caine, D. (1990). Injury predictors among female gymnasts' anthropometric and performance characteristics. In G. Hermans \& W. Mostard (Eds.), Sports, medicine and health (pp. 136-141). Excerpta Medica.

Logan, S., \& Medford, E. (2011). Gender differences in the strength of association between motivation, competency beliefs and reading skill. Educationa Research, 53(1), 85-94. https://doi.org/10.1080/00131881.2011.552242

Masten, R., Stražar, K., Žilavec, I., Tušak, M., \& Kandare, M. (2014). Psychological response of athletes to injury. Kinesiology, 46(1), 127-134. https://hrcak.srce. $\underline{\mathrm{hr} / 123742}$

Meyers, M., C., Bourgeois, A. E., \& LeUnes, A. (2001). Pain coping response of collegiate athletes involved in high contact, high injury-potential sport. International Journal of Sport Psychology, 32(1), 29-42.

Meyers, M. C., Bourgeois, A. E., Stewart, S., \& LeUnes, A. (1992). Predicting pain response in athletes: Development and assessment of the Sports Inventory for Pain. Journal of Sport and Exercise Psychology, 14(3), 249-261. https://doi. org/10.1123/isep.14.3.249

Meyers, M. C., Higgs, R., LeUnes, A. D., Bourgeois, A. E., \& Laurent, C. M. (2015). Pain-coping traits of nontraditional women athletes: Relevance to optimal treatment and rehabilitation. Journal of Athletic Training, 50(10), 1034-1041. https://doi.org/10.4085/1062-6050-50.8.04

Meyers, M. C., Stewart, C. C., Laurent, C. M., LeUnes, A. D., \& Bourgeois, A. E. (2008). Coping skills of Olympic developmental soccer athletes. International Journal of Sports Medicine, 29(12), 987-993. https://doi. org/10.1055/s-2008-1038679

Minev, M., Petkova, M., Petrova, B., \& Strebkova, R. (2017). Body awareness and responses to experimentally induced pain. Trakia Journal of Sciences, 15(3), 244-248. https://doi.org/10.15547/tis.2017.03.011

Nicholls, A. R., Polman, R. C., Levy, A. R., \& Backhouse, S. H. (2009). Mental toughness in sport: Achievement level, gender, age, experience, and sport type differences. Personality and Individual Differences, 47(1), 73-75. https:// doi.org/10.1016/i.paid.2009.02.006
Nixon, H. L. (1994). Social pressure, social support, and help seeking for pain and injuries in college sports networks. Journal of Sport and Social Issues, 18(4), 340-355. https://doi.org/10.1177/019372394018004004

Nixon, H. L. (1996). Explaining pain and injury attitudes and experiences in sport in terms of gender, race, and sports status factors. Journal of Sport and Social Issues, 20(1), 33-44. https://doi.org/10.1177/019372396020001004

Paller, C. J., Campbell, C. M., Edwards, R. R., \& Dobs, A. S. (2009). Sex-based differences in pain perception and treatment. Pain Medicine, 10(2), 289-299. https://doi.org/10.1111/i.1526-4637.2008.00558.x

Paulson, P. E., Minoshima, S., Morrow, T. J., \& Casey, K. L. (1998). Gender differences in pain perception and patterns of cerebral activation during noxious heat stimulation in humans. Pain, 76(1-2), 223-229. https://doi.org/10.1016/ S0304-3959(98)00048-7

Raudenbush, B., Canter, R. J., Corley, N., Grayhem, R., Koon, J., Lilley, S., Meyer, B., \& Wilson, I. (2012). Pain threshold and tolerance differences among intercollegiate athletes: Implication of past sports injuries and willingness to compete among sports teams. North American Journal of Psychology, 14(1), 85-94.

Salma, C. L., \& Meyers, M. C. (2019). Athletic and pain coping skills of competitive female equestrian athletes. Journal of Sport Behavior, 42(1), 91-108.

Sternberg, W. F., Bailin, D., Grant, M., \& Gracely, R. H. (1998). Competition alters the perception of noxious stimuli in male and female athletes. Pain, 76(1-2) 231-238. https://doi.org/10.1016/S0304-3959(98)00050-5

Sullivan, M. J., Thorn, B., Haythornthwaite, J. A., Keefe, F., Martin, M., Bradley, L. A., \& Lefebvre, J. C. (2001). Theoretical perspectives on the relation between catastrophizing and pain. Clinical Journal of Pain, 17(1), 52-64. https://doi. org/10.1097/00002508-200103000-00008

Sullivan, M. J., Tripp, D. A., Rodgers, W. M., \& Stanish, W. (2000). Catastrophizing and pain perception in sport participants. Journal of Applied Sport Psychology, 12(2), 151-167. https://doi.org/10.1080/10413200008404220

Tesarz, J., Schuster, A. K., Hartmann, M., Gerhardt, A., \& Eich, W. (2012). Pain perception in athletes compared to normally active controls: A systematic review with meta-analysis. Pain, 153(6), 1253-1262. https://doi.org/10.1016/i pain.2012.03.005

Thibault, V., Guillaume, M., Berthelot, G., El Helou, N., Schaal, K., Quinquis, L., Nassif, H., Tafflet, M., Escolano, S., Hermine, O., \& Toussaint, J. F. (2010). Women and men in sport performance: The gender gap has not evolved since 1983. Journal of Sports Science \& Medicine, 9(2), 214-223. https://www.jssm.org/ issm-09-214.xml\%3EFulltext

Thornton, C., Sheffield, D., \& Baird, A. (2017). A longitudinal exploration of pain tolerance and participation in contact sports. Scandinavian Journal of Pain, 16(1), 36-44. https://doi.org/10.1016/j.sjpain.2017.02.007

Thornton, C., Sheffield, D., \& Baird, A. (2019). Motor performance during experimental pain: The influence of exposure to contact sports. European Journal of Pain, 23(5), 1020-1030. https://doi.org/10.1002/eip.1370

Unruh, A. M. (1996). Gender variations in clinical pain experience. Pain, 65(2-3), 123-167. https://doi.org/10.1016/0304-3959(95)00214-6

Wahl, C. A., Gnacinski, S. L., Nai, M. M., \& Meyer, B. B. (2019). Psychological predictors of perceived stress and recovery in sport. Sport, Exercise, and Performance Psychology, 9(3), 292-307. https://doi.org/10.1037/spy0000175

Wandner, L. D., Devlin, A. S., \& Chrisler, J. C. (2011). Sports-related pain: Exploring the perception of athletes' pain. Athletic Insight Journal, 3, 41-57.

Wiesenfeld-Hallin, Z. (2005). Sex differences in pain perception. Gender Medicine, 2(3), 137-145. https://doi.org/10.1016/S1550-8579(05)80042-7

Williams, O. J. R. (2012). Athletic identity and hypercompetitiveness: Impact on athletes' attitudes toward pain and sport related injury [Doctoral dissertation, University of Oklahoma]. https://hdl.handle.net/11244/318489

Wise, E. A., Price, D. D., Myers, C. D., Heft, M. W., \& Robinson, M. E. (2002). Gender role expectations of pain: Relationship to experimental pain perception. Pain, 96(3), 335-342. https://doi.org/10.1016/S0304-3959(01)00473-0

Wood, W., \& Karten, S. J. (1986). Sex differences in interaction style as a product of perceived sex differences in competence. Journal of Personality and Social Psychology, 50(2), 341-347. https://doi.org/10.1037/0022-3514.50.2.341

Wooten, J. S., Meyers, M. C., Fincher, A. L., O'Connor, D., \& Woods, W. (2002). Pain coping responses of patients following anterior cruciate ligament reconstruction and rehabilitation. Medicine \& Science in Sports \& Exercise, 34(5), S161. https://iournals.Iww.com/acsm-msse/Fulltext/2002/05001/PAIN COPING RESPONSES OF PATIENTS FOLLOWING.906.aspx

Young, K., White, P., \& McTeer, W. (1994). Body talk: Male athletes reflect on sport, injury, and pain. Sociology of Sport Journal, 11(2), 175-194. https://doi. org/10.1123/ssj.11.2.175 